\title{
Impact of hepatic steatosis on treatment response in nuclesos(t)ide analogue-treated HBeAg-positive chronic hepatitis B: a retrospective study
}

Yi-Cheng Chen ${ }^{1,2^{*}+} \mathbb{D}$, Wen-Juei Jeng ${ }^{1,2+}$, Chao-Wei Hsu ${ }^{1,2}$ and Chun-Yen Lin ${ }^{1,2}$

\begin{abstract}
Background: The impact of hepatic steatosis (HS) on treatment response following nucleos(t)ide analogue (NA) treatment for chronic hepatitis B (CHB) patients has not been clearly elucidated. We aimed to investigate the difference in HBeAg seroclearance between NA-treated HBeAg-positive CHB patients with and without HS.

Methods: We retrospectively recruited HBeAg-positive CHB patients receiving liver biopsy and NA monotherapy. The baseline clinical characteristics and cumulative incidence of HBeAg seroclearance were compared between patients with and without HS and age/gender-matched subgroup analysis was performed.

Results: A total of 196 patients were enrolled from 2003 April to 2016 October. The mean age was $39.6 \pm 11.2$ years, $142(72.4 \%)$ were males and 94 (48\%) had histological evidence of HS. Median treatment duration and follow-up period were 24.3 months and 54.9 months, respectively. HBeAg seroclearance was achieved in 56/102 (54.9\%) and $54 / 94(57.4 \%)$ patients with and without $\mathrm{HS}$, respectively $(p=0.830)$. The 5 -year cumulative incidence of $\mathrm{HBeAg}$ seroclearance in patients with and without HS was 62.8 and $67.7 \%$ in overall population $(p=0.398)$ and 62.4 and $66.9 \%$ in age/gender-matched subgroups ( $p=0.395)$, respectively. The rate of HBeAg seroclearance was comparable between patients with or without HS in different NA monotherapy (all $p>0.05$ ).
\end{abstract}

Conclusions: HS had no significant impact on HBeAg seroclearance in HBeAg-positive CHB patients with NA monotherapy during long-term follow-up.

Keywords: Chronic hepatitis B, Hepatic steatosis, HBeAg seroclearance, Nucleos(t)ide analogue treatment

\footnotetext{
*Correspondence: yichengliver@gmail.com

${ }^{\dagger}$ Yi-Cheng Chen and Wen-Juei Jeng contributed equally to this work.

'Department of Gastroenterology and Hepatology, Chang Gung Memorial

Hospital, and University, Linkou, No 5, Fu Hsing Street, Guishan Dist, Taoyuan

City 33302, Taiwan, Republic of China

${ }^{2}$ College of Medicine, Chang Gung University, No.259, Wen Hua 1st Rd.,

Guishan Dist, Taoyuan City 33302, Taiwan, Republic of China
}

(c) The Author(s). 2020 Open Access This article is licensed under a Creative Commons Attribution 4.0 International License, which permits use, sharing, adaptation, distribution and reproduction in any medium or format, as long as you give appropriate credit to the original author(s) and the source, provide a link to the Creative Commons licence, and indicate if changes were made. The images or other third party material in this article are included in the article's Creative Commons licence, unless indicated otherwise in a credit line to the material. If material is not included in the article's Creative Commons licence and your intended use is not permitted by statutory regulation or exceeds the permitted use, you will need to obtain permission directly from the copyright holder. To view a copy of this licence, visit http://creativecommons.org/licenses/by/4.0/ The Creative Commons Public Domain Dedication waiver (http://creativecommons.org/publicdomain/zero/1.0/) applies to the data made available in this article, unless otherwise stated in a credit line to the data. 


\section{Background}

Chronic hepatitis B virus (HBV) infection is an important worldwide public health burden. There are approximately 250 million patients infected by HBV in the world [1]. The global prevalence of nonalcoholic fatty liver disease (NAFLD) is around 25\% [2], affecting 17 to $46 \%$ of adult population in Western countries and 8 to $54 \%$ in Asia $[3,4]$. The prevalence of hepatic steatosis in HBV-infected patients has been found to be $14-76 \%$ [ 5 , 6]. There has been reported that HBV infection is associated with a lower risk of fatty liver development [7-9] and that hepatic steatosis (HS) is inversely associated with HBV DNA levels $[6,10,11]$ under the hypothesis of viral replication attenuation $[12,13]$. Two studies in Taiwan have pointed out that moderate and severe HS were associated with increased odds ratio of HBsAg seroclearance [14] and body mass index (BMI) $\geq 30 \mathrm{~kg} / \mathrm{m}^{2}$ was a significant predictor of HBsAg seroclearance [15]. However, the impact of HS on antiviral treatment response in CHB has not been clearly elucidated.

$\mathrm{HBeAg}$ seroconversion is one of the therapeutic goals in $\mathrm{HBeAg}$-positive $\mathrm{CHB}$ patients. Past studies have shown an equivocal association between HS and treatment response to pegylated interferon in $\mathrm{CHB}$ patients [16-18]. Some studies in Asian regions have reported different results in HBeAg seroconversion under HS (by histology or noninvasive methods) in nucleos(t)ide analogues (NAs) treated CHB patients [19-23]. With such conflicting observations in the effect of $\mathrm{HS}$ on $\mathrm{HBeAg}$ seroconversion under NA treatment, we conducted a retrospective study to explore the impact of biopsyproven steatosis on treatment response in NA-treated HBeAg-positive CHB patients.

\section{Methods}

\section{Patients}

This retrospective study would recruit HBeAg-positive patients who were scheduled for NA treatment between 2003 April to 2016 October in Chang Gung Memorial Hospital, Linkou branch. All the enrolled patients had received liver biopsy before NA monotherapy and were treated for at least 12 months. Patients with hepatocellular carcinoma, co-infection with hepatitis $\mathrm{C}$ virus (HCV), hepatitis D virus (HDV) or human immunodeficiency virus (HIV), autoimmune, alcoholic and drug-induced liver diseases were excluded.

In Taiwan, antiviral therapy is reimbursed in $\mathrm{HBeAg}$ positive $\mathrm{CHB}$ patients under the criteria of (1) positive $\mathrm{HBeAg}>3$ months and alanine aminotransferase (ALT) $\geq 5 \mathrm{x}$ upper limit of normal (ULN); or (2) positive HBeAg $>3$ months, ALT 2-5x ULN, and HBV DNA $\geq 20,000 \mathrm{IU} /$ $\mathrm{mL}$ or positive $\mathrm{HBcAg}$ in histology. The duration of reimbursement has been extended to the time of $\mathrm{HBeAg}$ seroclearance with one-year consolidation therapy since
2017 January. Antiviral therapy can be reimbursed indefinitely in cirrhotic patients with HBV DNA > $2000 \mathrm{IU} /$ $\mathrm{mL}$ regardless of ALT levels.

This study was approved by Institutional Review Board (IRB) of Chang Gung Memorial Hospital (IRB No. 201701168B0).

\section{Laboratory measurements and definitions of treatment response}

The baseline clinical characteristics collected from the electronic medical records included aspartate aminotransferase (AST), ALT, total bilirubin, platelet count, $\mathrm{HBeAg}$, anti-HBe, anti-HCV, anti-HDV, HBV genotype, HBV DNA and quantitative HBsAg (qHBsAg). Stored serums were retrieved for assays of HBV genotype, HBV DNA or qHBsAg for any incomplete data. HBV genotype was determined by polymerase chain reactionrestriction fragment length polymorphism of the surface gene of HBV. Serum HBV DNA was assayed by COBAS ${ }^{\circ}$ AmpliPrep/COBAS ${ }^{\circ}$ TaqMan $^{\circ} \mathrm{HBV}$ Test, version 2.0 (lower limit of detection: $20 \mathrm{IU} / \mathrm{mL}$, Roche Diagnostics, Mannheim, Germany). Serum HBsAg levels were quantified using the Roche Elecsys HBsAg II quant assay (detection limit, 0.05-52,000 IU/mL; Roche Diagnostics, Mannheim, Germany) according to the manufacturer's instructions. $\mathrm{HBeAg}$, anti-HBe, anti-HCV and anti-HDV were tested with enzyme immunoassay kit (Abbott Diagnostics, North Chicago, IL).

$\mathrm{HBeAg}$ seroclearance was defined as $\mathrm{HBeAg}$ loss with or without the presence of anti-HBe in serial tests [21] during treatment or within 12 months after discontinuation of treatment without clinical flare-up (ALT $\geq 2 x U L N$ and HBV DNA $>2000 \mathrm{IU} / \mathrm{mL}$ ). Virological response (VR) was defined as a serum HBV DNA level < $20 \mathrm{IU} / \mathrm{mL}$ or undetectable after NA treatment. Patients with missing values or no stored serum available for assay of HBV DNA were regarded as non-VR. HBeAg reversion was defined as reappearance of $\mathrm{HBeAg}$ after HBeAg seroclearance. HBeAg-negative hepatitis was defined as persistent $\mathrm{HBeAg}$ negativity with $\mathrm{HBV}$ DNA > $2000 \mathrm{IU} / \mathrm{mL}$ and ALT increasing to $>2 \mathrm{x}$ ULN. HBsAg seroclearance was defined as HBsAg negativity for at least 12 months with or without the presence of antiHBs until the last visit [24].

\section{Histological assessment}

HS was defined as the presence of steatosis in over 5\% of hepatocytes according to the Brunt criteria [25]. Histological steatosis was categorized into score 0 to 3 [<5\%, 5-33\% (mild), > 33-66\% (moderate) and $>66 \%$ (severe)] [26]. The fibrosis score was graded by Metavir or Ishak scoring system [27, 28]. A fibrosis scores of 4 by Metavir or 5 and 6 by Ishak scores were considered cirrhosis. 


\section{Statistical analysis}

Continuous variables are expressed as means and standard deviations (S.D.) or medians and interquartile ranges (IQR) as appropriate after testing for normal distribution using the Kolmogorov-Smirnov test and are compared by independent Student's $t$-test or Mann-Whitney-U test between the groups with and without HS. One-way ANOVA or Kruskal-Wallis $\mathrm{H}$ test was performed to compare the difference of clinical characteristics among patients with different degrees of HS. Categorical variables were presented as the number of cases (proportions) and compared by Chi-squared or Fisher's exact tests when appropriate. The Kaplan-Meier method with the log-rank test was used to compare the cumulative rate of $\mathrm{HBeAg}$ seroclearance between patients with and without HS. The patients with and without HS would be matched by age ( \pm 1 year) and gender in 1:1 ratio for further analysis. Cox proportional hazards regression analysis was performed to find the associated predictors for HBeAg seroclearance. Variables with $p<0.1$ in univariate analysis were further analyzed in multivariate analysis. Patients were censored at the time of antiviral retreatment or until the last follow-up visit. Statistical analysis was performed by Statistics Package for Social Science (SPSS) software (version 22.0, SPSS Inc., Chicago, IL, USA). A two-tailed $p<0.05$ was considered statistically significant.

\section{Results}

\section{Baseline clinical characteristics}

A total of 196 consecutive $\mathrm{HBeAg}$-positive patients were enrolled in this study. The mean age was $39.6 \pm 11.2$ years, 142 (72.4\%) were males, 159 (81.1\%) were treatment-naïve, 94 (48\%) had histological HS and 59 (30.1\%) had cirrhosis. The NA treatment included lamivudine (LAM) in 75 (38.3\%), adefovir dipivoxil (ADV) in 2 (1\%), entecavir (ETV) in 61 (31.1\%), telbivudine (LdT) in $46(23.5 \%)$ and tenofovir disoproxil fumarate (TDF) in 12 (6.1\%). Baseline clinical characteristics between patients with and without $\mathrm{HS}$ are shown in Table 1. Patients with HS were significantly older (42.7 vs. 36.2 years, $p<0.001)$, had higher BMI $\left(25.2\right.$ vs. $22.7 \mathrm{~kg} / \mathrm{m}^{2}$, $p<0.001$ ), higher proportion of male gender (79.4 vs. $64.9 \%, p=0.035)$, genotype $C(57.4$ vs. $35.5 \%, p=0.004)$ and cirrhosis (39.2 vs. $20.2 \%, p=0.006)$ than those without HS. The mean qHBsAg level was significantly lower in patients with HS than those without (3.7 vs. $4.0 \mathrm{log}$ $\mathrm{IU} / \mathrm{mL}, p=0.009$ ).

\section{Treatment response and associated factors for $\mathrm{HBeAg}$ seroclearance}

After a median treatment duration of 24.3 months, HBeAg seroclearance was achieved in 110 (56.1\%) patients (54 in non-steatosis and 56 in steatosis, $p=0.830$ ) during a median follow-up period of 54.9 months. There were $40(36.4 \%)$ patients with $\mathrm{HBeAg}$ seroclearance at the time of 12 months. Among those staying in this study without retreatment during follow-up, additional $\mathrm{HBeAg}$ seroclearance occurred in $29(18.6 \%)$ at 24 months, $18(17.8 \%)$ at 36 months, $13(21 \%)$ at 48 months and $4(11.4 \%)$ at 60 months (Supplementary Table 1). A total of 104 (53.1\%) patients achieved HBeAg seroclearance at 5-year follow-up (anti-HBe occurred in 83 patients). The remaining 6 patients developed $\mathrm{HBeAg}$ seroclearance at $69.7,78,85.3,88,95.4$, and 105.3 months of follow-up.

The mean age at HBeAg seroclearance was significantly older in patients with HS than those without HS (45.6 vs. 38.5 years, $p=0.001$ ), while the median time to HBeAg seroclearance was comparable between these two groups (16.9 vs. 17.8 months, $p=0.401$ ) (Table 1 ). VR was achieved in $50(53.2 \%)$ and $65(63.7 \%)$ patients with and without HS, respectively $(p=0.177)$. There were 10 patients (2 HS and 8 non-HS) regarded as nonVR due to missing values for HBV DNA. After excluding these patients, VR was still not different between two groups $(p=0.419)$. The overall 5 -year cumulative incidence of HBeAg seroclearance was $64.9 \%$. The cumulative incidences of $\mathrm{HBeAg}$ seroclearance at 1 year, 3 years and 5 years were $21.6,42.5$ and $62.8 \%$ in patients with HS and 19.1, 56.2 and $67.7 \%$ in those without HS, respectively ( $p=0.398$ at 5 years, Fig. 1a). There was no significant difference in the rates of $\mathrm{HBeAg}$ reversion $(p=0.266)$, HBeAg-negative hepatitis $(p=0.491)$ and HBsAg seroclearance $(p=1.000)$ after HBeAg seroclearance between patients with and without HS (Table 1). There were 24 patients (20 cirrhosis) with continuous NA treatment until the last follow-up and 106 (54.1\%) patients were retreated during follow-up period (12 HBeAg revision, $31 \mathrm{HBeAg}$-negative hepatitis and 63 persistent $\mathrm{HBeAg}$-positivity with relapse).

HBeAg seroclearance occurred in 29 (38.7\%), 44 (72.1\%), 29 (63\%), 0 and 8 (66.7\%) in patients treated with LAM, ETV, LdT, ADV and TDF, respectively. There was no difference in HBeAg seroclearance between HS and non-HS patients in LAM $(p=0.334)$, ETV $(p=1.000)$, LdT $(\mathrm{p}=1.000)$ and $\operatorname{TDF}(p=0.576)$ treatment (Supplementary Table 2). The rate of VR was not statistically different between HS and non-HS patients in $\operatorname{LAM}(p=0.381), \operatorname{ETV}(p=0.392), \operatorname{LdT}(p=1.000)$ and TDF $(p=1.000)$ treatment.

The Cox proportional hazard regression analysis was performed to determine the factors associated with $\mathrm{HBeAg}$ seroclearance by the baseline variables of age, gender, HBV genotype, treatment naïve, cirrhosis, HS, AST, ALT, total bilirubin, platelet count, antiviral treatment, qHBsAg and HBV DNA levels. The patients with $\mathrm{ADV}$ and TDF treatment were not included in the 
Table 1 Comparison of baseline clinical characteristics and treatment response between HBeAg-positive patients with and without hepatic steatosis (HS)

\begin{tabular}{|c|c|c|c|c|c|c|c|}
\hline & \multicolumn{4}{|c|}{ Overall population } & \multicolumn{3}{|c|}{ Age/gender-matched subgroups } \\
\hline & Total & HS (-) & $\mathrm{HS}(+)$ & $p$ & $\mathrm{HS}(-)$ & $\mathrm{HS}(+)$ & $p$ \\
\hline No & 196 & 94 & 102 & & 56 & 56 & \\
\hline Age at treatment, year & $39.6 \pm 11.2$ & $36.2 \pm 10.8$ & $42.7 \pm 10.8$ & $<0.001$ & $38.5(31-44)$ & $39(31-44)$ & 0.930 \\
\hline Male & $142(72.4)$ & $61(64.9)$ & $81(79.4)$ & 0.035 & $43(76.8)$ & $43(76.8)$ & 1.000 \\
\hline $\mathrm{BMI}, \mathrm{kg} / \mathrm{m}^{2}$ & $24.0 \pm 3.2$ & $22.7 \pm 2.8$ & $25.2 \pm 3.1$ & $<0.001$ & $23.0 \pm 3.0$ & $25.0 \pm 3.0$ & 0.003 \\
\hline Genotype & & & & 0.004 & & & 0.087 \\
\hline B & $100(53.5)$ & $60(64.5)$ & $40(42.6)$ & & $35(62.5)$ & $23(44.2)$ & \\
\hline C & $87(46.5)$ & $33(35.5)$ & $54(57.4)$ & & $21(37.5)$ & $29(55.8)$ & \\
\hline Treatment-naïve & $159(81.1)$ & 77 (81.9) & $82(80.4)$ & 0.929 & $43(76.8)$ & $45(80.4)$ & 0.818 \\
\hline Cirrhosis & $59(30.1)$ & $19(20.2)$ & $40(39.2)$ & 0.006 & $13(23.2)$ & $17(30.4)$ & 0.522 \\
\hline AST, U/L & $62(42-89)$ & $65(42-108)$ & $62(42-84)$ & 0.254 & $72(45-137)$ & $61(38-84)$ & 0.060 \\
\hline$A L T, U / L$ & $106(68-167)$ & $121(75-211)$ & $102(62-153)$ & 0.098 & $124(79-216)$ & $99(68-154)$ & 0.111 \\
\hline Total bilirubin, mg/dL & $0.8(0.7-1.0)$ & $0.8(0.7-1.1)$ & $0.8(0.6-1.0)$ & 0.114 & $1.0(0.7-1.2)$ & $0.8(0.6-1.0)$ & 0.018 \\
\hline Platelet, $10^{9} / \mathrm{L}$ & $190(155-224)$ & $198(160-231)$ & $183(154-218)$ & 0.141 & $190.8 \pm 46.7$ & $194.6 \pm 45.7$ & 0.676 \\
\hline qHBsAg, log IU/mL & $3.8 \pm 0.7$ & $4.0 \pm 0.6$ & $3.7 \pm 0.8$ & 0.009 & $4.0 \pm 0.6$ & $3.8 \pm 0.8$ & 0.182 \\
\hline HBV DNA, log IU/mL & $7.7(6.8-8.3)$ & $7.9(7.1-8.3)$ & $7.5(6.5-8.1)$ & 0.165 & $7.6 \pm 1.0$ & $7.4 \pm 1.3$ & 0.259 \\
\hline Antiviral treatment & & & & 0.676 & & & 0.961 \\
\hline LAM & 75 (38.3) & $40(42.6)$ & $35(34.3)$ & & $24(42.9)$ & $22(39.3)$ & \\
\hline ADV & $2(1.0)$ & $1(1.1)$ & $1(1.0)$ & & $1(1.8)$ & $1(1.8)$ & \\
\hline LdT & $46(23.5)$ & $23(24.5)$ & $23(22.5)$ & & $12(21.4)$ & $15(26.8)$ & \\
\hline ETV & $61(31.1)$ & 25 (26.6) & $36(35.3)$ & & $16(28.6)$ & $16(28.6)$ & \\
\hline TDF & $12(6.1)$ & $5(5.3)$ & $7(6.9)$ & & $3(5.4)$ & $2(3.6)$ & \\
\hline Treatment duration, m & $24.3(12.2-36.8)$ & $24.3(12.2-36.5)$ & $23.7(12.1-36.6)$ & 0.306 & $23.8(12.2-36.5)$ & $24.3(12.1-36.6)$ & 0.835 \\
\hline Follow-up, m & $54.9(31.3-99.3)$ & $59.6(33.7-102.9)$ & $45.2(30.7-94.2)$ & 0.145 & $55.1(26.1-103.2)$ & 50.9 (31.9-92.7) & 0.979 \\
\hline \multicolumn{8}{|l|}{ Treatment response } \\
\hline HBeAg seroclearance & $110(56.1)$ & $54(57.4)$ & $56(54.9)$ & 0.830 & $30(53.6)$ & $28(50)$ & 0.850 \\
\hline Virological response & $115(58.7)$ & $50(53.2)$ & $65(63.7)$ & 0.177 & $28(50)$ & $32(57.1)$ & 0.570 \\
\hline Age at e seroclearance & $42.1 \pm 11.7$ & $38.5 \pm 11.4$ & $45.6 \pm 11.0$ & 0.001 & $41.5 \pm 11.1$ & $41.4 \pm 10.2$ & 0.959 \\
\hline Time to seroclearance, m & $17.5(9.3-34.8)$ & $17.8(8.9-28.6)$ & $16.9(9.4-39.9)$ & 0.401 & $23.9(15.4-38.8)$ & $29.4(16.0-45.5)$ & 0.436 \\
\hline HBeAg reversion ${ }^{a}$ & $13(11.8)$ & $4(7.4)$ & $9(16.1)$ & 0.266 & $2(6.7)$ & $3(10.7)$ & 0.665 \\
\hline HBeAg(-) hepatitis ${ }^{a}$ & $35(31.8)$ & $15(27.8)$ & $20(35.7)$ & 0.491 & $9(30)$ & $10(35.7)$ & 0.854 \\
\hline HBsAg seroclearance & $8(4.1)$ & $4(4.3)$ & $4(3.9)$ & 1.000 & $2(3.6)$ & $4(7.1)$ & 0.679 \\
\hline
\end{tabular}

Data were presented as mean \pm S.D. or median (interquartile range) and number (\%)

Hepatic steatosis, histologic steatosis > 5\%; BMI Body mass index; AST Aspartate aminotransferase; ALT Alanine aminotransferase; qHBsAg Quantitative HBsAg; LAM, lamivudine; ADV Adefovir dipivoxil; LdT Telbivudine; ETV Entecavir; TDF Tenofovir disoproxil fumarate

${ }^{a}$ Data analyzed based on $\mathrm{HBeAg}$ seroclearance

analysis because of small number of patients. In univariate analysis, gender (male vs female, hazard ratio [HR] $0.717,95 \%$ confidence interval $[\mathrm{CI}] 0.482-1.064, p=$ 0.099), antiviral treatment (ETV vs LAM, HR 1.602, 95\% CI $1.000-2.568, p=0.050$; LdT vs LAM, HR 1.841, 95\% CI $1.098-3.087, p=0.021$ ), qHBsAg (HR 0.756, 95\% CI $0.579-0.999, p=0.040$ ), and HBV DNA (HR 0.809, 95\% CI $0.686-0.955, p=0.012)$ were selected $(p<0.1)$ to be analyzed in multivariate analysis. Finally, only antiviral treatment (LdT vs LAM, HR 2.548, 95\% CI 1.338-4.853, $p=0.004$ ) and HBV DNA level (HR 0.729, 95\% CI $0.546-0.972, p=0.031$ ) were the independent factors for HBeAg seroclearance (Table 2). HS was not an associated factor in both univariate and multivariate analyses.

\section{Clinical characteristics and treatment response in different degrees of hepatic steatosis}

The comparison of baseline clinical characteristics and treatment response among 102 steatotic patients with different degrees of histological steatosis is shown in 


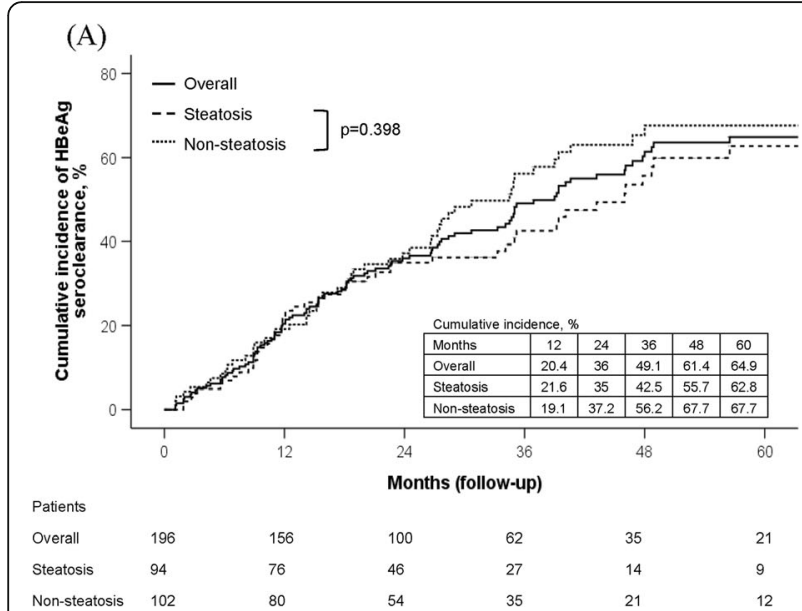

(B)

Fig. 1 The cumulative incidence of HBeAg seroclearance in HBeAg-positive patients treated with nucleos(t)ide analogues by Kaplan-Meier analysis and log-rank test. (A) Comparison between patients with and without hepatic steatosis in overall population $(N=196)$. The 5 -year cumulative incidence of HBeAg seroconversion was 62.8 and $67.7 \%$, respectively $(p=0.398)$. (B) Comparison between patients with and without hepatic steatosis in age- and gender-matched subgroups $(N=112)$. The 5 -year cumulative incidence of HBeAg seroclearance was 62.4 and $66.9 \%$, respectively $(p=0.395)$

Supplementary Table 3. As expected, patients with mild steatosis had significantly lower BMI $\left(24.3 \mathrm{~kg} / \mathrm{m}^{2}\right)$ than those with moderate steatosis $\left(26.2 \mathrm{~kg} / \mathrm{m}^{2}, p=0.043\right)$ and those with severe steatosis $\left(27.9 \mathrm{~kg} / \mathrm{m}^{2}, p=0.002\right)$ $(p=0.191$ in overall comparison). The patients with severe steatosis had significantly lower mean HBV DNA level than those with mild steatosis (6.6 vs 7.6 $\log \mathrm{IU} / \mathrm{mL}, p=0.036)$, while the difference was not significant $(p=0.531)$ as compared to the mean HBV DNA level $(7.1 \log \mathrm{IU} / \mathrm{mL})$ of those with moderate steatosis. The other clinical characteristics were comparable among these three groups. HBeAg seroclearance was achieved in 37 (57.8\%) with mild steatosis, 14 (56\%) with moderate steatosis and 5 (38.5\%) with severe steatosis $(p=0.438)$. The mean age at HBeAg seroclearance was $47.3,42.6$ and 40.8 years $(p=0.419)$ and the median time to $\mathrm{HBeAg}$ seroclearance was 17.7, 15.2 and 16 months $(p=0.898)$, respectively in the corresponding subgroups. The VR rate was similar among three groups $(p=0.875)$.

\section{$\mathrm{HBeAg}$ seroclearance in age- and gender-matched subgroups}

Since the age at $\mathrm{HBeAg}$ seroclearance was significantly older in patients with HS in present study, an impression rose that $\mathrm{HS}$ would delay $\mathrm{HBeAg}$ seroclearance, like the observation in a previous study [21]. We therefore matched the patients with and without $\mathrm{HS}$ by age $( \pm 1$ year $)$ and gender in 1:1 ratio and there were 56 patients in each group for further analysis. The mean BMI was significantly higher in patients with HS than those without HS (25 vs $23 \mathrm{~kg} /$ $\left.\mathrm{m}^{2}, p=0.003\right)$. The median total bilirubin level was significantly lower in patients with $\mathrm{HS}(0.8 \mathrm{mg} / \mathrm{dL})$ as compared to that in patients without $\mathrm{HS}(1.0 \mathrm{mg} / \mathrm{dL}$, $p=0.018)$. The other baseline clinical characteristics

Table 2 The associated factors for HBeAg seroclearance in the univariate and multivariate analyses

\begin{tabular}{|c|c|c|c|c|}
\hline \multirow[b]{2}{*}{ Factors } & \multicolumn{2}{|l|}{ Univariate } & \multicolumn{2}{|l|}{ Multivariate } \\
\hline & $\mathrm{HR}(95 \% \mathrm{Cl})$ & $\mathrm{p}$ & $\mathrm{HR}(95 \% \mathrm{Cl})$ & $p$ \\
\hline Gender ( $M$ vs F) & $0.717(0.482-1.064)$ & 0.099 & $0.667(0.404-1.099)$ & 0.112 \\
\hline \multicolumn{5}{|l|}{ Antiviral treatment } \\
\hline LAM & reference & & reference & \\
\hline ETV & $1.602(1.000-2.568)$ & 0.050 & $1.182(0.660-2.118)$ & 0.573 \\
\hline LdT & $1.841(1.098-3.087)$ & 0.021 & $2.548(1.338-4.853)$ & 0.004 \\
\hline $\mathrm{qHBsAg}, \log \mathrm{IU} / \mathrm{mL}$ & $0.756(0.579-0.999)$ & 0.040 & $0.755(0.515-1.107)$ & 0.150 \\
\hline HBV DNA, log IU/mL & $0.809(0.686-0.955)$ & 0.012 & $0.729(0.546-0.972)$ & 0.031 \\
\hline $\mathrm{HS}$ & $0.851(0.584-1.238)$ & 0.399 & $0.680(0.410-1.130)$ & 0.137 \\
\hline
\end{tabular}

Variables with $p<0.1$ in univariate analysis were analyzed in multivariate analysis

$H R$ Hazard ratio; Cl Confidence interval; qHBSAg Quantitative HBsAg; LAM lamivudine; LdT Telbivudine; ETV Entecavir; HS Hepatic steatosis 
were comparable between two subgroups (Table 1). The HBeAg seroclearance rate $(53.6$ vs $50 \%, p=$ 0.850 ), mean age at HBeAg seroclearance (41.5 vs 41.4 years, $p=0.959$ ) and median time to HBeAg seroclearance (23.9 vs 29.4 months, $p=0.436)$ were not statistically different between these two subgroups. HBeAg seroclearance occurred in 14 (30.4\%), 26 (81.3\%), 16 (59.3\%), 0 and $2(40 \%)$ in patients treated with LAM, ETV, LdT, ADV and TDF, respectively $(p<0.001)$. There was no significant difference in HBeAg seroclearance between patients with and without HS in LAM $(p=0.159)$, ETV $(p=0.654)$, LdT $(p=0.452)$ and TDF $(p=0.400)$ treatment (Supplementary Table 2). The 5 -year cumulative incidences of $\mathrm{HBeAg}$ seroclearance were comparable between patients with and without HS (62.4 vs $66.9 \%$ at 5 years, $p=0.395)$ (Fig. 1b).

\section{Discussion}

This is a real-world, retrospective study in Taiwan to discuss the impact of HS on HBeAg seroclearance in 196 HBeAg-positive patients with NA monotherapy based on the histological evidence, a gold standard for HS assessment $[2,3]$. The prevalence of HS in this cohort was $52 \%$, in accordance with those in previous reports ranging from 14 to $76 \%[5,6]$. The $\mathrm{HBeAg}$ seroclearance rate of $53 \%$ at 5 years was similar to that of $49 \%$ after 5-year TDF treatment [29]. According to the results, HS had no significant impact on treatment response in overall population and age/gender matched subgroups and among different NA monotherapy. This further confirmed the findings of previous studies using liver biopsy for HS evaluation [19, 21]. The studies discussing the influence of $\mathrm{HS}$ on HBeAg seroconversion/ seroclearance under antiviral treatment were summarized in Table 3.

As the NAFLD has become a common liver disease worldwide, the interaction between $\mathrm{CHB}$ and HS, as well as the associated metabolic syndrome and obesity, has been enthusiastically discussed recently. A pooled data in a systemic review [6] found a strong negative effect of HBV viral load on histology-proven HS [standardized mean difference -74.12 , 95\% CI $(-82.91,-65.31), p<$ 0.001]. An Indian study on $350 \mathrm{CHB}$ patients showed that the median HBV DNA was significantly lower in those with biopsy-proven HS $\left(6.9 \times 10^{5}\right.$ vs $7.5 \times 10^{6}$ copies $/ \mathrm{mL}, p=0.025)$ [11]. A recent study in Hong Kong [10] using CAP for HS assessment also found that the median HBV DNA levels were significantly lower in steatotic treatment-naïve patients when compared to non-steatotic controls ( 2.8 vs $3.1 \log \mathrm{IU} / \mathrm{mL}, p=0.011$ ). In our study, the patients with HS had lower median HBV DNA levels than non-HS patients but the difference was not statistically significant (7.5 vs $7.9 \log$ IU/ $\mathrm{mL}, p=0.165)$. Inclusion of patients with all $\mathrm{HBeAg}$ positivity, most in the status of immune clearance phase and nearly one-third being cirrhosis may explain this discrepancy in the statistical analysis.

Of note is that the steatotic HBeAg-positive patients had significantly lower mean qHBsAg levels than nonsteatotic patients ( 3.7 vs $4.0 \log \mathrm{IU} / \mathrm{mL}, p=0.009$ ) in this study and this inverse relationship was rarely discussed in past literatures. As the HBsAg production reflects the replication of HBV DNA and active transcription of covalently closed circular DNA (cccDNA) [30], fat deposition in hepatocytes may inhibit viral replication and downregulate transcription of cccDNA and therefore decrease the HBV-related antigen expression and production [12], such as HBsAg protein. Although this

Table 3 Summary of studies discussing the influence of hepatic steatosis on HBeAg seroclearance/seroconversion under antiviral treatment

\begin{tabular}{|c|c|c|c|c|c|}
\hline Source & Country & $\begin{array}{l}\text { Hepatic steatosis } \\
\text { (surrogate/method) }\end{array}$ & $\mathrm{HBeAg}(+) \mathrm{No}$ & Treatment & HBeAg seroconversion/seroclearance \\
\hline Charatcharoenwitthaya [19] & Thailand & Biopsy & 38 & IFN, LAM, ETV, TDF, LdT & $\begin{array}{l}\text { non-steatosis } 35 \% \text { vs steatosis } \\
27 \%, p=0.599\end{array}$ \\
\hline Chung [20] & Korea & $\mathrm{BMI} \geq 25 \mathrm{~kg} / \mathrm{m}^{2}$ & 44 & ETV & $\begin{array}{l}\text { Normal BMl } 36 \% \text { vs BMl } \geq 25 \mathrm{~kg} / \mathrm{m}^{2} \text {, } \\
p=0.695\end{array}$ \\
\hline Hsiang [21] & Hong Kong & MetS & $251\left(124^{\mathrm{a}}\right)$ & ETV, TDF & $\begin{array}{l}\text { Normal } 39.7 \% \text { vs pre-MetS } 49.6 \% \text { vs } \\
\text { MetS } 50 \% \text {; HR } 0.69 \text { in steatosis } \geq 34 \% \text {, } \\
p=0.36\end{array}$ \\
\hline $\operatorname{Jin}[22]$ & China & Ultrasound & 133 & ETV & $\begin{array}{l}\text { Steatosis } 24.6 \% \text { vs non-steatosis } \\
28.4 \%, p=0.13\end{array}$ \\
\hline Kim [23] & Korea & CAP & 172 & ETV, TDF & $\begin{array}{l}C A P<238 \mathrm{~dB} / \mathrm{m} 28.3 \% \text { vs } C A P \geq 238 \mathrm{~dB} / \mathrm{m} \\
13.8 \%, \mathrm{HR} 0.991 \text { in increasing CAP, } p=0.026\end{array}$ \\
\hline Present study & Taiwan & Biopsy & 196 & LAM, ADV, LdT, ETV, TDF & $\begin{array}{l}\text { Non-hepatic steatosis } 57.4 \% \text { vs hepatic } \\
\text { steatosis } 54.9 \%, p=0.830\end{array}$ \\
\hline
\end{tabular}

BMI Body mass index; CAP Controlled attenuation parameter; IFN Interferon; LAM Lamivudine; ADV Adefovir dipivoxil; LdT Telbivudine; ETV Entecavir; TDF tenofovir disoproxil fumarate; HR Hazard ratio; MetS metabolic syndrome

${ }^{a} 124$ patients had received liver biopsy 
discrepancy disappeared after age and gender adjustment, the patients with HS still had lower qHBsAg levels (3.8 vs $4.0 \log \mathrm{IU} / \mathrm{mL}$ ). Further and large-scaled studies are needed to explore this relationship. HBV genotype distribution was significantly different between patients with and without HS in overall population $(p=0.004)$. Even though the difference disappeared between age and gender-matched non-HS and HS subgroups $(p=0.087)$ (Table 1) which was coincident with previous reports [6, 11], the proportion of genotype $C$ was still higher in patients with HS. This paradoxical distribution of genotype $(\mathrm{C}>\mathrm{B})$ as compared to general population $(\mathrm{B}>\mathrm{C})$ in Taiwan needs to be clarified by more studies.

In a Hong Kong study [10] using transient elastography for liver stiffness measurement (LSM) and controlled attenuation parameter (CAP), severe steatosis was associated with an increased percentage of severe fibrosis $(23.2 \%$ vs $12.6 \%, p=0.005)$ in $\mathrm{CHB}$ patients. Metabolic syndrome, which is strongly associated with NAFLD, has been reported to increase the risk of liver fibrosis progression and cirrhosis development by LSM (adjust OR 2.0 for fibrosis progression, $p=0.015$; specificity $94 \%$ for cirrhosis) in CHB patients [31, 32]. These observations suggest that the co-existence of HS by indirect evidence can result in fibrosis progression in $\mathrm{CHB}$ patients. By contrast, the fibrosis staging was not different between CHB patients with or without histological HS in a meta-analysis including five studies (standardized mean difference $0.22, p=0.495$ ) [6]. The latter was further confirmed by the results in this study that patients with HS had significantly higher rate of liver cirrhosis (39.2 vs $20.2 \%, p=0.006$ ), but the difference was not significant between the age/gender-matched subgroups (30.4 vs $23.2 \%$, $p=0.522$ ). As histology is a gold standard for fibrosis staging in NAFLD, indirect evidence of HS like obesity, metabolic syndrome or CAP may be undesirable to specifically predict liver fibrosis in $\mathrm{CHB}$ patients and more validation is needed in the future. Regarding to the patients with different degrees of steatosis, there was no significant difference in the proportion of cirrhosis among mild, moderate and severe steatosis (36, 48 and $38.5 \%$, respectively, $p=0.577$ ) (Supplementary Table 3).

The impact of HS on treatment response to pegylated interferon in previous reports were controversial [16-18] and the association of HS with NA treatment response was also conflicting and has not been clearly elucidated so far. The study population in previous studies using liver biopsy for assessment of HS was number-limited and included patients with treatment by either pegylated interferon or NAs, both HBeAg-positive and HBeAg-negative or patients with antiviral treatment and treatment-free [19, 21]. In addition, some studies utilized indirect methods of BMI, ultrasound or CAP for clinical evaluation of HS [20, 22, 23]. By avoiding the heterogeneity in study population and study methods for HS assessment, this study was based on histological evidence of HS and recruited a larger number of HBeAg-positive patients $(n=196)$ and therefore could specifically explore the impact of $\mathrm{HS}$ on antiviral treatment response. The results came to comparable $\mathrm{HBeAg}$ seroclearance rate and no significant difference in the 5year cumulative incidence of $\mathrm{HBeAg}$ seroclearance between patients with and without HS. VR was also comparable between patients with and without HS. Based on the histologic evidence of $\mathrm{HS}$ and a homogenous cohort, we believed that our findings could provide a reliable inference that there is no significant impact of HS on treatment response under NA monotherapy.

In line with previous randomized global studies [33, 34], $\mathrm{HBeAg}$ seroclearance rates were significantly higher in patients with ETV treatment $(72.1 \%, p<0.001)$ and LdT treatment $(63 \%, p=0.016)$ than those with LAM treatment (38.7\%) in HBeAg-positive patients (Supplementary Table 2). In this study, both ETV and LdT were associated factors in $\mathrm{HBeAg}$ seroclearance relative to lamivudine in univariate analysis, while ETV, unlike LdT, lost this advantage in multivariate analysis (Table 2). This phenomenon could be explained by the heterogeneity of baseline clinical characteristics in patients with LAM, ETV and LdT treatment (supplementary Table 4). Older age and more patients with genotype C, cirrhosis and lower ALT were found in patients treated with ETV. In the results of this study, HS had no influence on the HBeAg seroclearance and VR among different NA treatment. In contrast to ETV, a recent study by Kim and his colleagues found the possibility of $\mathrm{HBeAg}$ loss was significantly lower in TDFtreated patients with hepatic steatosis [23]. Another study by Jin's team showed a significantly increased rate of HBV DNA clearance in ETV-treated patients without HS but not the rate of $\mathrm{HBeAg}$ seroconversion [22]. A study including 145 biopsy-proven CHB patients, HS had no impact on VR to ETV and TDF treatment [35]. Decreased bioavailability of intrahepatic metabolites [36] of NAs due to hepatocellular fat droplet accumulation has been supposed be the reason for the different performance of NAs in treatment response. Diminished activity of hepatic cytochrome in steatotic hepatocytes, insulin resistance and obesity coexisted HS leading to dysfunction of cellular immune function may also affect the treatment outcomes [22]. More studies are needed to elucidate the influence of HS to NA treatment.

There are some limitations in our study. First, enrolled patients were limited to the conditions of $\mathrm{HBeAg}$ positivity, with liver biopsy and NA monotherapy and therefore the prevalence of hepatic steatosis or the clinical discrepancy between patients with or without HS or with different NA treatment could not represent the general population of $\mathrm{CHB}$ and might raise study bias. Nonetheless, we had the advantage of liver biopsy in all enrolled patients, which 
would be difficult to approach in future prospective studies as noninvasive methods have emerged recently. We also tried to minimize the clinical difference by matching age and gender between patients with and without HS. Second, the results about the impact of HS on HBeAg seroclearance with NA treatment should be validated in Western countries because all the previous reports and this study are restricted to Asia-Pacific regions with predominant genotype $\mathrm{B}$ and $\mathrm{C}$. Third, there were insufficient data in metabolic profiles in our study for analysis. The effect of metabolic factors on treatment response is still a controversial issue. Although metabolic syndrome has been reported to delay HBeAg seroconversion [21], another study from Korea [37] showed that metabolic syndrome was not correlated with HBV DNA suppression and the cumulative rates of $\mathrm{HBeAg}$ negative conversion $(p=0.434)$ and seroconversion $(p=$ $0.119)$ under NA treatment. Fourth, as the patient recruitment started in the early era of NA treatment and liver biopsy was no more a prerequisite for $\mathrm{CHB}$ treatment after approval of ETV and TDF in Taiwan, only $37 \%$ of patients were treated with ETV or TDF in this study cohort. Finally, only 10 patients had nonalcoholic steatohepatitis (NASH) assessment since NASH evaluation began in late 2014 in pathological reporting system. HBeAg positivity persisted in one with NASH and 7 of the remaining 9 patients without $\mathrm{NASH}$ achieved $\mathrm{HBeAg}$ seroclearance. It has been reported that NASH did not affect response to antiviral therapy of interferon or NAs [19].

\section{Conclusions}

This study included a cohort of HBeAg-positive patients with histological evidence of HS under NA monotherapy and showed no significant difference in the cumulative incidence of HBeAg seroclearance between those with and without HS during long-term follow-up. This phenomenon was also observed in age/gender matched subgroups and patients with different NA monotherapy. Validation to the impact of HS on antiviral treatment response in HBV endemic areas with genotype non-B or non-C is warranted.

\section{Supplementary information}

Supplementary information accompanies this paper at https://doi.org/10. 1186/s12876-020-01289-w.

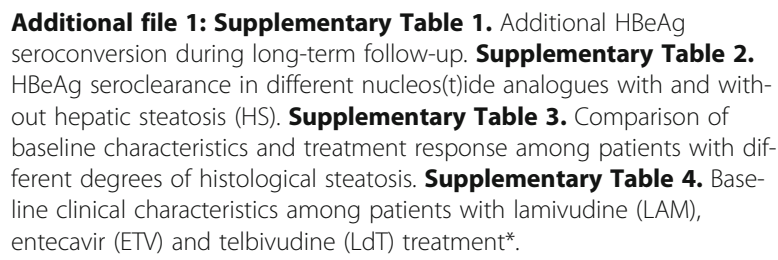

\section{Abbreviations}

HS: Hepatic steatosis; NA: Nucleos(t)ide analogue; CHB: Chronic hepatitis B; HBV: Hepatitis B virus; NAFLD: Nonalcoholic fatty liver disease; BMl: Body mass index; HCV: Hepatitis C virus; HDV: Hepatitis D virus; HIV: Human immunodeficiency virus; ALT: Alanine aminotransferase; ULN: Upper limit of normal; AST: Aspartate aminotransferase; IQR: Interquartile ranges;

LAM: Lamivudine; ADV: Adefovir dipivoxil; ETV: Entecavir; LdT: Telbivudine;

TDF: Tenofovir disoproxil fumarate; HR: Hazard ratio; Cl: Confidence interval;

VR: Virological response; NASH: Nonalcoholic steatohepatitis

\section{Acknowledgements}

The authors thank Ms. Li-Hwa Lu and I-Han Lin for assistance of data collection

\section{Authors' contributions}

Concept and design: Y-C C; Data acquisition, interpretation and analysis: $Y-C$ C, C-W H, W-J J, C-Y L; Drafting of the manuscript: Y-C C; Critical revision of the manuscript for important intellectual content: Y-C C, C-W H, W-J J, C-Y L; Statistical analysis: Y-C C, W-J J. All authors read and approved the final manuscript.

\section{Funding}

This work was supported by grants from Chang Gung Memorial Hospital (Grant Number: CORPG3G0631, CORPG3G0641, CORPG3G0651,

CORPG1G0041). The funder had no role in the design of the study and

collection, analysis, and interpretation of data and in writing the manuscript.

\section{Availability of data and materials}

The raw data collected and analyzed in the current study are not publicly available due to appropriate protection of patient personal information but are available from the corresponding author on reasonable request.

Ethics approval and consent to participate

This study protocol was reviewed and approved by the Institutional Review Board of Chang Gung Memorial Hospital (IRB No. 201701168B0).

\section{Consent for publication}

Not applicable.

\section{Competing interests}

The authors declare that they have no competing interests.

Received: 12 February 2020 Accepted: 30 April 2020

Published online: 12 May 2020

\section{References}

1. Schweitzer A, Horn J, Mikolajczyk RT, Krause G, Ott JJ. Estimations of worldwide prevalence of chronic hepatitis B virus infection: a systematic review of data published between 1965 and 2013. Lancet. 2015;386(10003): 1546-55.

2. Chalasani N, Younossi Z, Lavine JE, Charlton M, Cusi K, Rinella M, Harrison SA, Brunt EM, Sanyal AJ. The diagnosis and management of nonalcoholic fatty liver disease: practice guidance from the American Association for the Study of Liver Diseases. Hepatology. 2018;67(1):328-57.

3. European Association for the Study of the $L$, European Association for the Study of D, European Association for the Study of O. EASL-EASD-EASO clinical practice guidelines for the management of non-alcoholic fatty liver disease. J Hepatol. 2016;64(6):1388-402.

4. Seto WK, Yuen MF. Nonalcoholic fatty liver disease in Asia: emerging perspectives. J Gastroenterol. 2017;52(2):164-74.

5. Fan JG, Chitturi S. Hepatitis B and fatty liver: causal or coincidental? J Gastroenterol Hepatol. 2008;23(5):679-81.

6. Machado MV Oliveira AG, Cortez-Pinto H. Hepatic steatosis in hepatitis B virus infected patients: meta-analysis of risk factors and comparison with hepatitis C infected patients. J Gastroenterol Hepatol. 2011;26(9):1361-7.

7. Wong W, Wong GL, Chu WC, Chim AM, Ong A, Yeung DK, Yiu KK, Chu SH, Chan HY, Woo J, et al. Hepatitis B virus infection and fatty liver in the general population. J Hepatol. 2012;56(3):533-40.

8. Cheng YL, Wang YJ, Kao WY, Chen PH, Huo TI, Huang YH, Lan KH, Su CW, Chan WL, Lin HC, et al. Inverse association between hepatitis B virus infection and fatty liver disease: a large-scale study in populations seeking for check-up. PLoS One. 2013:8(8):e72049.

9. Joo EJ, Chang Y, Yeom JS, Ryu S. Hepatitis B virus infection and decreased risk of nonalcoholic fatty liver disease: a cohort study. Hepatology. 2017 65(3):828-35. 
10. Hui RWH, Seto WK, Cheung KS, Mak LY, Liu KSH, Fung J, Wong DK, Lai CL, Yuen MF. Inverse relationship between hepatic steatosis and hepatitis B viremia: results of a large case-control study. J Viral Hepat. 2018;25(1):97104.

11. Rastogi A, Sakhuja P, Kumar A, Hissar S, Jain A, Gondal R, Sarin SK. Steatosis in chronic hepatitis B: prevalence and correlation with biochemical, histologic, viral, and metabolic parameters. Indian J Pathol Microbiol. 2011; 54(3):454-9.

12. Zhang Z, Pan Q, Duan XY, Liu Q, Mo GY, Rao GR, Fan JG. Fatty liver reduces hepatitis $B$ virus replication in a genotype $B$ hepatitis $B$ virus transgenic mice model. J Gastroenterol Hepatol. 2012;27(12):1858-64.

13. Hu D, Wang H, Wang H, Wang Y, Wan X, Yan W, Luo X, Ning Q. Nonalcoholic hepatic steatosis attenuates hepatitis $B$ virus replication in an HBVimmunocompetent mouse model. Hepatol Int. 2018.

14. Chu CM, Lin DY, Liaw YF. Does increased body mass index with hepatic steatosis contribute to seroclearance of hepatitis B virus (HBV) surface antigen in chronic HBV infection? Int J Obes. 2007;31(5):871-5.

15. Liu J, Yang HI, Lee MH, Lu SN, Jen CL, Wang LY, You SL, Iloeje UH, Chen CJ, Group R-HS. Incidence and determinants of spontaneous hepatitis B surface antigen seroclearance: a community-based follow-up study. Gastroenterology. 2010;139(2):474-82

16. Cindoruk M, Karakan T, Unal S. Hepatic steatosis has no impact on the outcome of treatment in patients with chronic hepatitis B infection. J Clin Gastroenterol. 2007:41(5):513-7.

17. Ates F, Yalniz M, Alan S. Impact of liver steatosis on response to pegylated interferon therapy in patients with chronic hepatitis B. World J Gastroenterol. 2011;17(40):4517-22.

18. Gong L, Liu J, Wang J, Lou GQ, Shi JP. Hepatic Steatosis as a predictive factor of antiviral effect of Pegylated interferon therapy in patients with hepatitis B. Transplant Proc. 2015:47(10):2886-91.

19. Charatcharoenwitthaya $P$, Pongpaibul A, Kaosombatwattana U, Bhanthumkomol P, Bandidniyamanon W, Pausawasdi N, Tanwandee T. The prevalence of steatohepatitis in chronic hepatitis B patients and its impact on disease severity and treatment response. Liver Int. 2017;37(4):542-51.

20. Chung WG, Kim HJ, Choe YG, Seok HS, Chon CW, Cho YK, Kim Bl, Koh YY. Clinical impacts of hazardous alcohol use and obesity on the outcome of entecavir therapy in treatment-naive patients with chronic hepatitis $B$ infection. Clin Mol Hepatol. 2012;18(2):195-202.

21. Hsiang JC, Wong GL, Chan HL, Chan AW, Chim AM, Wong WW. Metabolic syndrome delays HBeAg seroclearance in Chinese patients with hepatitis B. Aliment Pharmacol Ther. 2014;40(6):716-26.

22. Jin $X$, Chen YP, Yang YD, Li YM, Zheng L, Xu CQ. Association between hepatic steatosis and entecavir treatment failure in Chinese patients with chronic hepatitis B. PLoS One. 2012;7(3):e34198.

23. Kim DS, Jeon MY, Lee HW, Kim BK, Park JY, Kim DY, Ahn SH, Han KH, Kim SU. Influence of hepatic steatosis on the outcomes of patients with chronic hepatitis B treated with entecavir and tenofovir. Clin Mol Hepatol. 2019; 25(3):283-93.

24. Chen YC, Jeng WJ, Chien RN, Chu CM, Liaw YF. Clinical outcomes after spontaneous and nucleos(t)ide analogue-treated $\mathrm{HBsAg}$ seroclearance in chronic HBV infection. Aliment Pharmacol Ther. 2016:43(12):1311-8.

25. Kleiner DE, Brunt EM. Nonalcoholic fatty liver disease: pathologic patterns and biopsy evaluation in clinical research. Semin Liver Dis. 2012;32(1):3-13.

26. Kleiner DE, Brunt EM, Van Natta M, Behling C, Contos MJ, Cummings OW, Ferrell LD, Liu YC, Torbenson MS, Unalp-Arida A, et al. Design and validation of a histological scoring system for nonalcoholic fatty liver disease. Hepatology. 2005;41(6):1313-21.

27. Desmet VJ, Gerber M, Hoofnagle JH, Manns M, Scheuer PJ. Classification of chronic hepatitis: diagnosis, grading and staging. Hepatology. 1994;19:1513-20.

28. Ishak K, Baptista A, Bianchi L, Callea F, De Groote J, Gudat F, Denk H, Desmet V, Korb G, MacSween RN. Histological grading and staging of chronic hepatitis. J Hepatol. 1995;22(6):696-9.

29. Marcellin P, Gane E, Buti M, Afdhal N, Sievert W, Jacobson IM, Washington MK, Germanidis G, Flaherty JF, Schall RA, et al. Regression of cirrhosis during treatment with tenofovir disoproxil fumarate for chronic hepatitis B: a 5-year open-label follow-up study. Lancet. 2013;381(9865):468-75.

30. Liaw YF. Clinical utility of hepatitis B surface antigen quantitation in patients with chronic hepatitis B: a review. Hepatology. 2011;54(2):E1-9.

31. Wong GL, Wong WW, Choi PC, Chan AW, Chim AM, Yiu KK, Chan HY, Chan FK, Sung JJ, Chan HL. Metabolic syndrome increases the risk of liver cirrhosis in chronic hepatitis B. Gut. 2009;58(1):111-7.
32. Wong GL, Chan HL, Yu Z, Chan AW, Choi PC, Chim AM, Chan HY, Tse CH, Wong W. Coincidental metabolic syndrome increases the risk of liver fibrosis progression in patients with chronic hepatitis B--a prospective cohort study with paired transient elastography examinations. Aliment Pharmacol Ther. 2014;39(8):883-93.

33. Chang TT, Gish RG, de Man R, Gadano A, Sollano J, Chao YC, Lok AS, Han $\mathrm{KH}$, Goodman Z, Zhu J, et al. A comparison of entecavir and lamivudine for HBeAg-positive chronic hepatitis B. N Engl J Med. 2006;354(10):1001-10.

34. Liaw YF, Gane E, Leung N, Zeuzem S, Wang Y, Lai CL, Heathcote EJ, Manns M, Bzowej N, Niu J, et al. 2-year GLOBE trial results: telbivudine is superior to lamivudine in patients with chronic hepatitis B. Gastroenterology. 2009; 136(2):486-95.

35. Ceylan B, Arslan F, Batirel A, Fincanci M, Yardimci C, Fersan E, Pasaoglu E, Yilmaz M, Mert A. Impact of fatty liver on hepatitis B virus replication and virologic response to tenofovir and entecavir. Turk J Gastroenterol. 2016; 27(1):42-6.

36. Lau E, Carvalho D, Freitas P. Gut microbiota: association with NAFLD and metabolic disturbances. Biomed Res Int. 2015;2015:979515.

37. Kim NH, Cho YK, Kim BI, Kim HJ. Effect of metabolic syndrome on the clinical outcomes of chronic hepatitis B patients with Nucleos(t)ide analogues treatment. Dig Dis Sci. 2018;63(10):2792-9.

\section{Publisher's Note}

Springer Nature remains neutral with regard to jurisdictional claims in published maps and institutional affiliations.
Ready to submit your research? Choose BMC and benefit from:

- fast, convenient online submission

- thorough peer review by experienced researchers in your field

- rapid publication on acceptance

- support for research data, including large and complex data types

- gold Open Access which fosters wider collaboration and increased citations

- maximum visibility for your research: over $100 \mathrm{M}$ website views per year

At $\mathrm{BMC}$, research is always in progress.

Learn more biomedcentral.com/submissions 